\title{
Sampling times and genotyping concerns in bioequivalence evaluation of branded and generic formulations
}

This article was published in the following Dove Press journal:

Therapeutics and Clinical Risk Management

23 November 2013

Number of times this article has been viewed

\section{Xiao-Ying Zhao' \\ Hui-Min $X u^{2}$ \\ Quan Zhou ${ }^{2}$}

'The Medical Ethics Committee, ${ }^{2}$ Department of Pharmacy, The Second Affiliated Hospital, School of Medicine, Zhejiang University, Hangzhou, Zhejiang Province, People's Republic of China
Correspondence: Quan Zhou

Department of Pharmacy, The Second Affiliated Hospital, School of Medicine, Zhejiang University, Zhejiang 310009 , People's Republic of China

Tel +86 57I 877846 I5

Fax $+8657 \mid 87022776$

Email zhouquan142602@zju.edu.cn

\section{Dear editor}

We read with great interest the study by Del Tacca et al, ${ }^{1}$ who performed a comparative pharmacokinetic (PK) and pharmacodynamic (PD) evaluation of branded and generic formulations of meloxicam in healthy male subjects, and concluded that the two products can be used interchangeably in clinical practice. We especially appreciate their exploratory study on the PD/PK relationship which provides an important reference for bioequivalence studies of analgesics. However, we found two points worthy of discussion and we would like to share our perspectives in the following paragraphs.

\section{Sampling times}

The design of the sampling times plays an important role in the reliability of the bioequivalence evaluation. A sufficient number of samples to adequately describe the plasma concentration-time profile should be collected. The sampling schedule should include frequent sampling around predicted time to maximal plasma concentration $\left(\mathrm{T}_{\max }\right)$ to provide a reliable estimate of peak exposure, and it should also cover the plasma concentration time curve long enough to provide a reliable estimate of the extent of exposure which will be achieved if area under the plasma concentration-time curve (AUC) from time zero to the last measurable concentration $\left(\mathrm{AUC}_{(0-t)}\right)$ covers at least $80 \%$ of $\mathrm{AUC}$ from time zero to infinity $\left(\mathrm{AUC}_{(0 \text {-inf })}\right){ }^{2}$ Generally at least three to four samples are needed during the terminal log-linear phase. ${ }^{2}$ The total sampling points (not including predose) should not be less than twelve. ${ }^{3}$ However, only eight blood samples, after dosing, per subject were taken in the study by Del Tacca et al. ${ }^{1}$ The duration of sampling is usually at least three times the terminal half-life $\left(\mathrm{t}_{1 / 2 \beta}\right)$ of the measured compound for immediaterelease products. ${ }^{3}$ However, a sampling period longer than 72 hours is not considered necessary for any immediate release formulation irrespective of the half-life of the drug. ${ }^{2}$ Literature shows that $t_{1 / 2 \beta}$ of meloxicam is approximately 20 hours., ${ }^{4,5}$ Theoretically, the last sampling point should be at least 60 hours after ingestion of meloxicam instead of 24 hours after dosing as in Del Tacca et al's study. The mean $\mathrm{AUC}_{(0-24)}$ and $\mathrm{AUC}_{(0-\text { inf })}$ values of meloxicam derived from a single dose of $15 \mathrm{mg}$ Mobic (Boehringer Ingelheim $\mathrm{GmbH}$, Ingelheim, Germany) were $18.49 \mathrm{mg} \times \mathrm{h} / \mathrm{L}$ and $33.25 \mathrm{mg} \times \mathrm{h} / \mathrm{L}$, respectively. Meloxicam $\mathrm{AUC}_{(0-t)}$ covered only $55.6 \%$ of the $\mathrm{AUC}_{(0-\mathrm{inf})}$, which was not in accordance with the criteria ( $\geq 80 \%$ ) established by European Medicines Agency (EMA) guidelines. Although this article notes that the main study objective is not to investigate the complete PK profiles of meloxicam in healthy volunteers but rather to compare PK and PD patterns between branded and generic meloxicam, the results of bioequivalence evaluation 
would be more convincing if the industry guideline was well followed, especially regarding that the lower limit of quantification (LLOQ) for the analytical method established by Del Tacca et al $^{1}$ has met the criteria of EMA (ie, higher than 1/20 of maximum concentration $\left.\left[\mathrm{C}_{\max }\right]\right)^{2}$

\section{Genotyping of subjects}

Potential sources of variability, such as genetic polymorphism, should be identified and taken into account when designing the bioequivalence study. Poor metabolizers (PMs) may be excluded from bioequivalence studies in order to minimize risk to subjects (ie, possible harm caused by prolonged exposure to high drug concentrations). ${ }^{6}$ EMA recommends that phenotyping and/or genotyping of subjects may be considered for safety or pharmacokinetic reasons. ${ }^{2}$ China's State Food and Drug Administration (SFDA) and The Association of Southeast Asian Nations (ASEAN) guidelines for the conduct of bioequivalence studies specify that studies could be performed in subjects of known phenotype or genotype for the polymorphism in question if a drug is known to be subject to major genetic polymorphism. ${ }^{7,8}$ However, global consensus is unavailable with regard to the inclusion or exclusion of poor versus extensive metabolizers (EMs) as a method to decrease variability.

We performed a PubMed search covering the period from 1988 to 15 September 2013, using the search terms "bioequivalence" and "genetic polymorphism or phenotype or genotype" and additional filters (species: humans; languages: English). Forty-three articles were detected. Inclusion criteria included studies addressing the relationship of bioequivalence evaluation and genetic polymorphism in metabolizing enzyme or transporter. Four articles were finally included under this search strategy. The full text of each article was critically reviewed, and data interpretation was performed (Table 1). ${ }^{9-12}$

Table I Relationship of bioequivalence evaluation and genetic polymorphism

\begin{tabular}{|c|c|c|c|}
\hline Drug & Drug metabolizing enzyme & Relationship & Recommendations \\
\hline Tenoxicam 9 & CYP2C9 & $\begin{array}{l}\text { The } 90 \% \text { confidence intervals of the treatment ratios for the } \\
\text { In-transformed values of } \mathrm{C}_{\max } \text { and } A \cup C_{(0-i n)} \text { were within } \\
\text { the preset bioequivalence range of } 80 \%-125 \% \text {, regardless of } \\
\text { all participants or either allelic variant subgroups. AUC } \\
\text { and } t_{1 / 2} \text { were influenced by the presence of CYP2C } 9 * 3 \text { allele } \\
\text { resulting in a high variability. A non-parametric analysis } \\
\text { indicated that the variability in } A \cup C_{(0-i n)} \text { increased to } \\
79 \%-117 \% \text { in CYP2C9*2 and to } 78 \%-177 \% \text { in CYP2C } 9 * 3 \text {. } \\
\text { Both groups were out of the accepted international } \\
\text { bioequivalence range. The cause of this variability will } \\
\text { be missed if genotyping is not performed. }\end{array}$ & $\begin{array}{l}\text { CYP2C9 genotyping prior to } \\
\text { a bioequivalence study is a } \\
\text { useful approach. }\end{array}$ \\
\hline Citalopram $^{10}$ & CYP2CI9 & $\begin{array}{l}\text { CYP2C19 PMs were excluded, based on genotyping of } \\
\text { genomic DNA from blood samples. Written informed } \\
\text { consent regarding genotyping was given by each candidate } \\
\text { before CYP2CI } 9 \text { genotype screening. Further written } \\
\text { informed consent for bioequivalence study was obtained } \\
\text { from twenty-four CYP2CI9 EMs after screening. The } 90 \% \\
\text { confidence intervals of the treatment ratios for the } \\
\text { In-transformed values of } \mathrm{C}_{\text {max }}, \mathrm{AUC}_{(0-t)} \text { and AUC } \mathrm{C}_{(0-\text { inf })} \text { were } \\
\text { within the predetermined acceptance range. }\end{array}$ & $\begin{array}{l}\text { Chinese have a higher } \\
\text { incidence of CYP } 2 \text { CI } 9 \text { PMs } \\
\text { compared with Caucasians } \\
\text { ( } 25 \% \text { versus } 2 \%-5 \%) \text {. To } \\
\text { ensure the safety of PMs } \\
\text { and exclude the influence } \\
\text { of CYP } 2 \text { C } 19 \text { genotype, } \\
\text { CYP } 2 \text { CI } 9 \text { EMs should be } \\
\text { chosen as subjects. }\end{array}$ \\
\hline Tacrolimus" & CYP3A5 & $\begin{array}{l}\text { The intra-subject coefficient of variations of } A \cup C_{(0-t)} \text { and } C_{\max } \\
\text { in the CYP3A5*3/3 group were about } 4 I .1 \% \text { and } 52.4 \% \\
\text { greater than those in the CYP3A5*I*I+*I/*3 group. The } \\
\text { estimated total sample size for the bioequivalence study } \\
\text { of tacrolimus with a } 2 \times 2 \text { cross-over design was increased } \\
\text { by } 93.3 \% \text { for AUC } C_{(0-t)}(n=30 \text { versus } 58) \text { and } 121.4 \% \text { for } \\
C_{\max }(n=28 \text { versus } 62) \text { in the CYP3A } 5 * 3 / * 3 \text { group } \\
\text { compared with the CYP3A } 5 * 1 / * 1+* 1 / * 3 \text { group. }\end{array}$ & $\begin{array}{l}\text { Genotyping for CYP3A5 } \\
\text { will provide a more efficient } \\
\text { approach for bioequivalence } \\
\text { designs. }\end{array}$ \\
\hline Mirtazapine ${ }^{12}$ & CYP2D6 & $\begin{array}{l}\text { A } 29.2 \% \text { or } 15.3 \% \text { sample size reduction would be possible } \\
\text { if the recruitment had been arranged for individuals carrying } \\
\text { just } 0 \text { or } 0 \text { plus I CYP2D6 active genes (ie, PMs, intermediate } \\
\text { metabolizers) due to the lower intra-individual variability. }\end{array}$ & $\begin{array}{l}\text { In the design of bioequivalence } \\
\text { studies of CYP2D6 substrates, } \\
\text { screening and genotyping may } \\
\text { play a role in reducing sample } \\
\text { size and costs. }\end{array}$ \\
\hline
\end{tabular}

Abbreviations: $\mathrm{AUC}_{(0-\mathrm{t})}$, area under the plasma concentration-time curve from time zero to the last measurable concentration; $A \cup \mathrm{C}_{(0-\mathrm{inf})}$, area under the plasma concentration-time curve from time zero to infinity; $\mathrm{C}_{\max }$, maximum concentration; CYP, cytochrome P450; EMs, extensive metabolizers; PMs, poor metabolizers. 
In bioequivalence studies, intra-individual variability is critical in determining sample size. Highly variable drugs are generally defined as those for which within-subject variability in AUC and/or $\mathrm{C}_{\max }>30 \% .{ }^{2}$ In order to conduct an acceptable bioequivalence study of a highly variable drug, higher numbers of subjects may be needed. ${ }^{13}$ With regard to the study by Del Tacca et al, coefficient of variation values were slightly above the recommended upper limit of $30 \%$ (34\% for $\mathrm{AUC}_{(0-24)}$ and $33 \%$ for $\mathrm{C}_{\max }$ ). Genetic polymorphisms in CYP2C9 could be one of the major source of pharmacokinetic variation. CYP2C9 genotype is expected to impact the clearance of meloxicam. ${ }^{14}$ There are several allelic variants of CYP2C9, the most common are the CYP2C9*2 and CYP2C9*3, with an allele frequency in the Caucasian population respectively of $8 \%-18 \%$ and $4 \%-10 \%$. CYP 2 C $9 * 2$ and CYP 2 C $9 * 3$ alleles show impaired activity. Subjects with genotype CYP2C9 $* 1 / * 1$ (frequency of $70 \%$ in the Caucasian population) are considered normal metabolizers; individuals CYP2C $9 * 1 / * 2$ (frequency of $16 \%$ in Caucasian populations), and $* 1 / * 3$ (frequency of $10 \%$ in the Caucasian population) are considered poor metabolizers; subjects with genotype of $* 2 / * 2$ (frequency of $1 \%$ ), $* 2 / * 3$ (frequency $1 \%$ ) or $* 3 / * 3$ (frequency of $0.3 \%$ ) are very poor metabolizers. ${ }^{15,16}$ Meloxicam is primarily metabolized to a $5^{\prime}$-hydroxymethyl metabolite by CYP2C9 (major) and CYP3A4 (minor) and the fraction of total cytochrome P450 metabolism catalyzed by CYP2C9 in EM (wild type, CYP2C $\left.9^{*} 1 / * 1\right)$ subjects $\left(f_{\mathrm{m}, \mathrm{CYP} 2 \mathrm{C} 9 \mathrm{(EM})}\right)$ is $\sim 0.8$. Tenoxicam is a cyclooxygenase (COX) inhibitor similar to meloxicam, with the same value of $\left.f_{\mathrm{m}, \mathrm{CYP} 2 \mathrm{C9}(\mathrm{EM})}\right)^{14}$ Salem et al recommended that CYP2C9 genotyping prior to a bioequivalence study of tenoxicam is a useful approach. ${ }^{9}$ So we postulate that it may also be applicable to meloxicam.

Furthermore, whether to perform pharmacogenetic screening prior to bioequivalence study also depends on population source. With regard to CYP2C9 genetic polymorphism, frequencies of CYP 2 C $9 * 1 / * 3$, CYP 2 C $9 * 1 / * 2$ in Chinese populations are $5.36 \%$ and $0.28 \%,{ }^{17}$ respectively, obviously lower than those in Caucasians (ie, $10 \%, 16 \%$, respectively). Therefore, genotyping prior to bioequivalence evaluation seems unnecessary for Chinese participants. On the contrary, with regard to CYP2C19 polymorphism, the situation is just the opposite. Incidence rate of CYP2C19 PMs in Chinese populations is far higher than that in Caucasians (25\% versus $2 \%-5 \%$ ), indicating that it is very necessary to perform genotyping or phenotyping of CYP2C19 prior to bioequivalence study of typical CYP2C19 substrates in Chinese subjects.

Del Tacca et al's study along with our perspectives may introduce an interesting topic. As stated by Del Tacca et al, prescribing physicians cannot access any information on the preregistration development of generic drugs, and they can only trust that the regulatory authority approved a specific generic product in full accordance with recommended guidelines. Anyhow, bioequivalence study is a method of evaluating quality of generic formulations. For this purpose, both study design and variation factor control cannot be overestimated.

\section{Acknowledgment}

This work was supported by National Natural Science Foundation of China grant 81373488, and National Major Projects of China grants 2012ZX09506001-004.

\section{Disclosure}

The authors report no conflicts of interest in this communication.

\section{References}

1. Del Tacca MD, Pasqualetti G, Gori G, et al. Comparative pharmacokinetic and pharmacodynamic evaluation of branded and generic formulations of meloxicam in healthy male volunteers. Ther Clin Risk Manag. 2013; 9:303-311.

2. Committee for Medical Products for Human use, European Medicines Agency. Guideline on the investigation of bioequivalence. Aug 2010 [webpage on the Internet]. Available from: http://www.ema.europa. eu/docs/en_GB/document_library/Scientific_guideline/2010/01/ WC500070039.pdf. Accessed September 14, 2013.

3. Health Products and Food Branch. Health Canada. Guidance document: Conduct and Analysis of Comparative Bioavailability. May 2010 [webpage on the Internet]. Available from: http://www.hc-sc.gc.ca/ dhp-mps/alt_formats/pdf/prodpharma/applic-demande/guide-ld/bio/ gd_cbs_ebc_ld-eng.pdf. Accessed September 14, 2013.

4. Davies NM, Skjodt NM. Clinical pharmacokinetics of meloxicam. A cyclo-oxygenase-2 preferential nonsteroidal anti-inflammatory drug. Clin Pharmacokinet. 1999;36:115-126.

5. Tangsucharit P, Kampan J, Kanjanawart S, et al. Bioequivalence study of two meloxicam tablet formulations after single-dose administration in healthy Thai male volunteers. Int J Clin Pharmacol Ther. 2009; 47:638-642.

6. Welage LS, Kirking DM, Ascione FJ, Gaither CA. Understanding the scientific issues embedded in the generic drug approval process. $J \mathrm{Am}$ Pharm Assoc (Wash). 2001;41:856-867.

7. State Food and Drug Administration of China. Guideline for Bioavailability and Bioequivalence studies of pharmaceutical formulations [in Chinese]. Available from: http://www.sfda.gov.cn/ WS01/CL0055/10368.html. Accessed September 13, 2013.

8. ASEAN Guidelines for the Conduct of Bioavailability and Bioequivalence Studies. http://www.hsa.gov.sg/publish/etc/medialib/ hsa_library/health_products_regulation/western_medicines/files_guidelines.Par.59188.File.dat/ACTR_GuidelinesforConductofBioavailabi lityandBioequivalenceStudies_Nov05.pdf. Accessed September 13, 2013.

9. Salem MS, Alkaysi HN, Gharaibeh AM, Gharaibeh NM, Badwan AA. Bioequivalence of two oral dosage forms prepared from different polymorphic modifications of tenoxicam. J Clin Pharm Ther. 1994; 19:203-207.

10. Jiang T, Rong Z, Xu Y, et al. Pharmacokinetics and bioavailability comparison of generic and branded citalopram $20 \mathrm{mg}$ tablets: an openlabel, randomized-sequence, two-period crossover study in healthy Chinese CYP2C19 extensive metabolizers. Clin Drug Investig. 2013;33:1-9. 
11. Yong Chung J, Jung Lee Y, Bok Jang S, Ahyoung Lim L, Soo Park M, Hwan Kim K. CYP3A5*3 genotype associated with intrasubject pharmacokinetic variation toward tacrolimus in bioequivalence study. Ther Drug Monit. 2010;32:67-72.

12. González-Vacarezza N, Abad-Santos F, Carcas-Sansuan A, et al. Use of pharmacogenetics in bioequivalence studies to reduce sample size: an example with mirtazapine and CYP2D6. Pharmacogenomics $J$. June 26, 2012.

13. Patterson SD, Zariffa NMD, Montague TH, Howland K. Nontraditional study designs to demonstrate average bioequivalence for highly variable drug products. Eur J Clin Pharmacol. 2001;57: 663-670.

14. Rodrigues AD. Impact of CYP2C9 genotype on pharmacokinetics: are all cyclooxygenase inhibitors the same? Drug Metab Dispos. 2005;33:1567-1575.
15. RealGene. http://www.realgene.it/dettaglio_prodotto.asp?language= eng\&id_a=42. Accessed September 13, 2013.

16. Zhou Q, Chen QX, Ruan ZR, Yuan H, Xu HM, Zeng S. CYP2C9*3(1075A \&gt; C), ABCB1 and SLCO1B1 genetic polymorphisms and gender are determinants of inter-subject variability in pitavastatin pharmacokinetics. Pharmazie. 2013;68:187-194.

17. Dai DP, Xu RA, Hu LM, et al. CYP2C9 polymorphism analysis in Han Chinese populations: building the largest allele frequency database. Pharmacogenomics J. Epub February 12, 2013. 


\section{Authors' reply}

\author{
Mario Del Tacca ${ }^{1,2}$ \\ Giuseppe Pasqualetti ${ }^{3}$ \\ Giovanni Gori' \\ Pasquale Pepe' \\ Antonello Di Paolo² \\ Marianna Lastella ${ }^{2}$ \\ Ferdinando De Negri \\ Corrado Blandizzi ${ }^{2}$
}

'Clinical Pharmacology Centre for Drug Experimentation,

Pisa University Hospital, Pisa, Italy; ${ }^{2}$ Division of Pharmacology,

Department of Clinical and Experimental Medicine, University of

Pisa, Pisa, Italy; ${ }^{3}$ Geriatrics Unit, University of Pisa, Pisa, Italy

Correspondence: Mario Del Tacca

Clinical Pharmaology Centre for Drug Experimentation, Pisa University

Hospital, 67 Via Roma, Pisa 56100, Italy

Tel +39050993954

Fax +39050 99343

Email m.deltacca@gmail.com

\section{Dear editor}

We thank Zhao et al for their interest in our clinical research article on the post-marketing evaluation of the bioequivalence between generic and branded formulations of meloxicam, recently published in Therapeutic and Clinical Risk Management. ${ }^{1}$

Two main points of criticism have been raised by Zhao et al on our paper: the number of time-points included in the pharmacokinetic (PK) evaluation of meloxicam, and the genotyping of enrolled subjects for the hepatic enzymes involved in the metabolic disposition of meloxicam.

With regard to the first issue, Zhao et al argue that a number of blood samples not less than twelve (instead of 8 samples, as done in our study) would have allowed a more accurate estimation of the area under the concentration-time curve (AUC) from time 0 to the last measurable concentration (ie, at least 60 hours after meloxicam administration, instead of the 24-hour interval after dosing, followed up in our study). In addition, Zhao et al underline the importance of fully complying with the guidelines of the European Medicine Agency (EMA), which recommends the estimation of AUC values covering $\geq 80 \%$ of the AUC $(0-\infty){ }^{2}$

To address the above comments, we wish to remark that our main study objective was not to investigate the overall PK profile of meloxicam in healthy volunteers, since this information has been previously published by several authors. ${ }^{3-6}$ Our primary aim was instead to perform a post-marketing inves- tigation to highlight putative PK differences between generic and brand meloxicam formulations marketed in Italy. On this basis, we designed a time span of blood sampling sufficient to cover both the dissolution and absorption PK phases, assuming that the distribution and elimination phases should not be significantly affected by the pharmaceutical forms. Moreover, we introduced a pharmacodynamic (PD) test as a secondary endpoint into the study design, with the purpose of exploring the feasibility of assessing the analgesic activity of meloxicam in healthy volunteers, and its role as a potential surrogate parameter. Indeed, we considered that a PK test in healthy subjects may provide a unique chance for assessing also a PD surrogate endpoint, while the evaluation of hard clinical endpoints (ie, analgesic efficacy) would require far larger sample sizes of patients enrolled in randomized, double blind, controlled, parallel group trials. Accordingly, our study was carried out to evaluate whether the PD outcome was consistent with meloxicam plasma concentrations assessed around the time to maximal plasma concentration $\left(\mathrm{T}_{\max }\right)$ which lies in between the absorption/distribution phase. In this setting, we performed a PD test, modifying that described by Chassaing et al, ${ }^{7}$ which explored the analgesic effect of meloxicam during the maximum plasma concentration period (around $\mathrm{T}_{\max }$ ) which occurs about 5-6 hours after dosing. By the combined evaluation of the PK and PD profiles of meloxicam we sought to stress the concept that a comparative PD study, for testing the response to hyperalgesic stimuli in healthy volunteers, might represent a useful tool for better estimating the putative therapeutic equivalence of two formulations containing the same analgesic, particularly in the post-marketing setting. ${ }^{8}$ Finally, it was just by virtue of the post-marketing nature of our study in healthy subjects, that the Ethical Committee of Pisa University Hospital imposed a limitation of the study period, with a parallel limitation of blood sampling, recommending to span the minimum time needed to determine the primary endpoint (ie, the PK comparison for bioequivalence assessment).

As far as the genotyping of healthy volunteers is concerned, we agree in principle with the issue raised by Zhao et al. Indeed, the knowledge of the genetic status of a cohort of individuals, enrolled to investigate bioequivalence, could contribute to rule out a number of factors known to influence the variability of drug pharmacokinetics. However, we must consider also some important points of discussion in this matter. Meloxicam is mainly metabolized through the CYP2C9 isoform, whereas CYP3A4 appears to play a minor role. ${ }^{910}$ For these CYP isoforms, and in particular for the CYP2C members, more than 50 polymorphisms have been 
described, but an alteration of the enzymatic function has not been established for any of them. Furthermore, the most frequent variant alleles of CYP2C9 among Caucasians are $* 2$ and $* 3$, with minor allele frequencies (MAFs) of about $10 \%-17 \%$ and $>10 \%$, respectively. ${ }^{11}$ Based on these data, in our population of healthy volunteers we could expect less than $5 \%$ of homozygotes for the polymorphic allele (ie, one subject out of 24, when adopting a maximum MAF of 0.2 ) and $9 \%-16 \%$ of heterozygotes (approximately two to four subjects among the 24 enrolled). Of note, the presence of this/ these individual(s) would have been identified just looking at his/their drug plasma profiles (for example, by an increase of about 1.6-2.2 times in AUC values), without any need for genotyping. ${ }^{12}$ Furthermore, in a crossover design, where each subject (either mutated or not) represents his own control, the $\mathrm{AUC}$ or $\mathrm{C}_{\max }$ ratios of the two meloxicam formulations are expected to be not affected by polymorphisms. Even when performing genotyping, it remains unknown whether the phenotypes expressed in heterozygotes and homozygotes (be they wild-type or polymorphic in nature) can be distinguished or not for a specific drug, and, among the different polymorphisms, which one/s should be investigated. In the case of tenoxicam, it has been observed that PK variations are significant in the presence of a heterozygous genotype for the CYP2C9*13 variant, ${ }^{13}$ but this variant allele has been mainly found in East Asia populations and appears to be poorly represented in Caucasians. ${ }^{14}$ Finally, it is clear that the enrollment of healthy volunteers (or patients) on a genetic basis for performing post-marketing bioequivalence studies can lead to considerable cost increments. Besides these considerations, at the time of our study planning, current guidelines on bioequivalence trials did not recommend any pharmacogenetic testing. ${ }^{15}$

Overall, while we do sincerely believe that the conclusions drawn in our study are not undermined by clinically or regulatory relevant $\mathrm{PK}$ or pharmacogenetic issues, we acknowledge the appreciation of Zhao et al for our attempt of proposing $\mathrm{PK} / \mathrm{PD}$ relationship as important reference for post-marketing bioequivalence studies on analgesic drugs.

\section{Disclosure}

The authors report no conflicts of interest in this communication.

\section{References}

1. Del Tacca M, Pasqualetti G, Gori G, et al. Comparative pharmacokinetic and pharmacodynamics evaluation of branded formulations of meloxicam in healthy male volunteers. Ther Clin Risk Manag. 2013; 9:303-311.

2. European Medicines Agency. Guideline on the investigation of bioequivalence. 2010. Available from: http://www.emea.europa. eu/docs/en_GB/document_library/Scientific_guideline/2010/01/ WC500070039.pdf. Accessed October 15, 2013.

3. Ahmad M, et al. Bioequivalence study of two brands of meloxicam tablets in healthy human Pakistani male subjects. Acta Pol Pharm. 2011;68:115-119.

4. Hasan SM, et al. Bioequivalence studies of two brands of meloxicam tablets in healthy Pakistani volunteers. Pak J Pharm Sci. 2009;22:199-204.

5. Tangsucharit $\mathrm{P}$, et al. Bioequivalence study of two meloxicam tablet formulations after single-dose administration in healthy Thai male volunteers. Int J Clin Pharmacol Ther. 2009;47:638-642.

6. Gschwend MH, et al. Pharmacokinetic and bioequivalence study of meloxicam tablets in healthy male subjects. Arzneimittelforschung. 2007;57:264-268.

7. Chassaing C, Schmidt J, Eschalier A, Cardot JM, Dubray C. Hyperalgesia induced by cutaneous freeze injury for testing analgesics in healthy volunteers. Br J Clin Pharmacol. 2006;61(4):389-397.

8. Meredith P. Bioequivalence and other unresolved issues in generic drug substitution. Clin Ther. 2003;25:2875-2890.

9. Schmid J, Busch U, Heinzel G, Bozler G, Kaschke S, Kummer M. Pharmacokinetics and metabolic pattern after intravenous infusion and oral administration to healthy subjects. Drug Metab Dispos. 1995;23:1206-1213.

10. Chesne C, Guyomard C, Guillouzo A, Schmid J, Ludwig E, Sauter T. Metabolism of meloxicam in human liver involves cytochromes P4502C9 and 3A4. Xenobiotica. 1998;28:1-13.

11. Xie HG, Prasad HC, Kim RB, Stein CM. CYP2C9 allelic variants: ethnic distribution and functional significance. Adv Drug Deliv Rev. 2002;54:1257-1270.

12. Rodrigues AD. Impact of CYP2C9 genotype on pharmacokinetics: are all cyclooxygenase inhibitors the same? Drug Metab Dispos. 2005;33: $1567-1575$.

13. Vianna-Jorge R, Perini JA, Rondinelli E, Suarez-Kurtz G. CYP2C9 genotypes and the pharmacokinetics of tenoxicam in Brazilians. Clin Pharmacol Ther. 2004;76:18-26.

14. Si D, Guo Y, Zhang Y, Yang L, Zhou H, Zhong D. Identification of a novel variant CYP2C9 allele in Chinese. Pharmacogenetics. 2004;14: 465-469.

15. European Medicines Agency. Note for guidance on the investigation of bioavailability and bioequivalence. Available from: http://www.ema. europa.eu/docs/en_GB/document_library/Scientific_guideline/2009/09/ WC500003519.pdf. Accessed October 15, 2013.
Therapeutics and Clinical Risk Management

\section{Publish your work in this journal}

Therapeutics and Clinical Risk Management is an international, peerreviewed journal of clinical therapeutics and risk management, focusing on concise rapid reporting of clinical studies in all therapeutic areas, outcomes, safety, and programs for the effective, safe, and sustained use of medicines. This journal is indexed on PubMed Central, CAS,

\section{Dovepress}

EMBase, Scopus and the Elsevier Bibliographic databases. The manuscript management system is completely online and includes a very quick and fair peer-review system, which is all easy to use. Visit $\mathrm{http}: / /$ www.dovepress.com/testimonials.php to read real quotes from published authors. 